\title{
Candida auris: patógeno fúngico emergente é detectado no
}

\section{HErista}

\author{
EDITORIAL
}

No dia 07 de dezembro de 2020, a Agência Nacional de Vigilância Sanitária (Anvisa), publicou o alerta de risco da identificação do primeiro possível caso positivo de Candida auris ( $C$. auris) no Brasil. O fungo foi identificado em amostra de ponta de cateter de paciente do sexo masculino de 59 anos internado por complicações da Covid-19 em UTI adulto em um hospital do estado da Bahia, sendo confirmado pela técnica MALDI-TOF MS (Matrix-Assisted Laser Desorption Ionization Time-of-Light Mass Sepctrometry) no Laboratório Central de Saúde Pública Professor Gonçalo Moniz (Lacen/BA) e no Laboratório do Hospital das Clínicas da Faculdade de Medicina da Universidade de São Paulo (HCFMUSP). ${ }^{1}$

As análises fenotípicas para verificação do perfil de susceptibilidade da levedura às drogas antifúngicas e o sequenciamento genético da região ITS e/ou D1/D2 do rDNA do microrganismo (padrão-ouro) foram concluídos no dia 09 de dezembro de 2020, pelo Laboratório Especial de Micologia da Escola Paulista de Medicina (LEMI-Unifesp), conforme publicado no Alerta de Risco GVIMS/GGTES/Anvisa no 02/2020 confirmando laboratorialmente o primeiro caso de $C$. auris no Brasil. ${ }^{2}$

O teste de suscetibilidade aos antifúngicos foi realizado pela técnica de microdiluição em caldo de acordo com o protocolo do CLSI M27. Foram verificadas as concentrações inibitórias mínimas (CIMs) de $2 \mathrm{mg} / \mathrm{L}$ para fluconazol, 0,5mg/L para anfotericina $B$, e $0,06 \mathrm{mg} / \mathrm{L}$ para anidulafungina. Os CIMs obtidos para fluconazol e anfotericina $B$ são menores que os classicamente reportados para a espécie. ${ }^{2}$ Porém, em caso de suspeita de infecção invasiva por $C$. auris, equinocandinas devem ser consideradas a primeira opção terapêutica. ${ }^{3}$

A levedura $C$. auris é uma nova espécie de candida, descrita pela primeira vez em 2009, no Japão, isolada do conduto auditivo de um paciente. Tem sido isolada de diversos sítios anatômicos de pacientes de países da Europa, América do Norte, América do Sul, Ásia, África e Oceania. Infecção e colonização é descrita principalmente em pacientes críticos internados em unidades de terapia intensiva (UTIs), incluindo adultos e crianças. Tem a capacidade de colonizar nos pacientes e permanecer em superfícies como paredes e leitos hospitalares, o que facilita a sua disseminação no ambiente hospitalar. ${ }^{3}$

C. auris é causadora de infecções hematogênicas e outras infecções invasivas, principalmente em pa- cientes com comorbidades e imunossupressão, devido a dificuldade de identificação pelos métodos de rotina empregados nos laboratórios de análises clínicas, e pode causar surtos de infecções relacionadas a assistência à saúde (Iras), principalmente no ambiente hospitalar. ${ }^{3}$

Considerada um fungo emergente que representa uma séria ameaça a saúde pública, pois é multirresistente às drogas antifúngicas, incluindo a classe dos azóis, derivados poliênicos e equinocandinas, a $C$. auris pode permanecer viável por longos períodos no ambiente (semanas ou meses) e apresenta resistência a diversos desinfetantes, entre os quais, os que são à base de quartenário de amônio. Além disso, sua identificação é dificultada, pois não existem técnicas laboratoriais de rotina, capazes de identificá-la. ${ }^{3}$

Em outubro de 2016, a Organização Pan-Americana da Saúde/Organização Mundial da Saúde (Opas/ OMS) publicou um alerta epidemiológico em função dos relatos de surtos de $C$. auris em serviços de saúde da América Latina, recomendando aos Estados-membros a adoção de medidas de prevenção e controle de surtos decorrentes deste patógeno. ${ }^{4}$

Em 14 de março de 2017, a Anvisa publicou o Comunicado de Risco no 01/2017 - GVIMS/GGTES/ Anvisa, contendo orientações para a vigilância laboratorial, encaminhamento de isolados para laboratórios de referência e as medidas de prevenção e controle de Iras pela $C$. auris. Além disso, esse documento definiu a Rede Nacional para identificação de $C$. auris em serviços de saúde, que analisa amostras suspeitas que são encaminhadas pelos estados. 4

Prakash et $a^{5}$ descreveram a identificação molecular de cinco isolados de um hospital brasileiro em novembro de 2015, os quais apresentaram altas CIMs para todos aos antifúngicos testados (fluconazol, voriconazol, anfotericina B e caspofungina). Entretanto, somente em março de 2017, a Anvisa publicou o comunicado de risco de relatos de surtos de $C$. auris em serviços de saúde na América Latina, com as recomendações para triagem e encaminhamento de amostras suspeitas para centro de referências para identificação. Então, somente a partir de 2017 os serviços de saúde no Brasil começaram a realizar a triagem de amostras suspeitas.

A dificuldade na deteç̧ão e identificação dessa nova levedura emergente se deve ao fato das técnicas micológicas clássicas de cultivo e identificação bioquími- 
ca das leveduras não permitirem a diferenciação da $C$. auris de outras leveduras. Também pode ser confundida com outras leveduras como Candida haemulonii, Candida famata, Candida sake, Candida catenulata, Candida Iusitaniae/Candida guilliermondii (sistema automatizado Microscan), Saccharomyces cerevisiae e Rhodotorula glutinis (sistema automatizado API-20). ${ }^{3-4}$

Portanto, atualmente a identificação de C. auris deve ser realizada através de técnicas moleculares de MALDI-TOF MS ou sequenciamento. O comunicado de risco da Anvisa determina provas de triagem para identificação presuntiva da $C$. auris em laboratórios que não possuem as metodologias moleculares para identificação. Em caso positivo nas provas de triagem, os isolados devem ser reservados para posterior análise e a Comissão de Controle de Infecção Hospitalar (CCIH) do serviço de saúde de origem deve ser imediatamente informada da suspeita de infecção por $C$. auris. A CCIH deve entrar em contato com a Coordenação Estadual de Controle de Infecção Hospitalar (CECIH) para solicitar autorização de encaminhamento do isolado para o Laboratório Central (Lacen) do estado para identificação molecular. ${ }^{4}$

Das et al6, em novembro de 2020, descreveram um meio seletivo para isolamento de $C$. auris. O meio YPD (Yeast Peptone Dextrose) suplementado com $12,5 \%$ de cloreto de sódio e $9 \mathrm{mM}$ de sulfato ferroso que apresentou $100 \%$ de especificidade e sensibilidade no isolamento seletivo da levedura após incubação a $42^{\circ} \mathrm{C}$ por $72 \mathrm{~h}$. A maioria das linhagens (95\%) apresentou crescimento após $48 \mathrm{~h}$ de incubação à $42^{\circ} \mathrm{C}$. O meio é de baixo custo e fácil preparação, surgindo como uma alternativa viável para detecção do fungo na rotina dos laboratórios de microbiologia.

Devido à dificuldade no diagnóstico e à característica de multirresistência e virulência de $C$. auris, é necessário um incremento na vigilância laboratorial para detecção dessa nova levedura em todos os serviços de saúde do país, reforçar as medidas gerais de prevenção e controle de IRAS e, em caso de suspeita ou confirmação de $C$. auris, adotar imediatamente as medidas de prevenção e controle previstas no Comunicado de Risco no 01/2017 - GVIMS/GGTES/Anvisa - Relatos de surtos de Candida auris em serviços de saúde da América Latina. ${ }^{4}$

\section{REFERÊNCIAS}

1. Agência Nacional de Vigilância Sanitária (BR). Brasil: Alerta de Risco GVIMS/GGTES/Anvisa no 01/2020. Identificação de possível caso de Candida auris no Brasil; 07 de dezembro de 2020. [acesso em 07 dez 2020]. Disponível em: https:// www.gov.br/anvisa/pt-br/assuntos/noticias-anvisa/2020/identificacao-de-possivel-caso-de-candida-auris-no-brasil/ALERTA012020CANDIDAAURIS07.12.2020_2.pdf
2. Agência Nacional de Vigilância Sanitária (BR). Brasil: Alerta de Risco GVIMS/GGTES/Anvisa no 02/2020. Confirmação de caso de Candida auris no Brasil.; 09 de dezembro de 2020. [acesso em 07 dez 2020]. Disponível em: https://www.gov.br/anvisa/ pt-br/centraisdeconteudo/publicacoes/servicosdesaude/comunicados-de-risco-1/alerta-02-2020-candida-auris-09-12-2020. pdf

3. Jeffery-Smith A, Taori SK, Schelenz S, Jeffery K, Johnson EM, Borman $A$ et al. Candida auris: a review of the literature. Clinical microbiology reviews, 2018; 31(1). doi: 10.1128/CMR.0002917

4. Agência Nacional de Vigilância Sanitária (BR). Brasil: Comunicado de Risco No 01/2017 GVIMS/GGTES/Anvisa. Relatos de surtos de Candida auris em serviços de saúde da América Latina; 14 de março de 2017. [acesso em 07 dez 2020]. Disponível em: https://www20.anvisa.gov.br/segurancadopaciente/index. php/alertas/item/comunicado-de-risco-01-2017-candida-auris

5. Prakash A, Sharma C, Singh A, Singh PK, Kumar A, Hagen $F$ et al. Evidence of genotypic diversity among Candida auris isolates by multilocus sequence typing, matrix-assisted laser desorption ionization time-of-flight mass spectrometry and amplified fragment length polymorphism. Clinical Microbiology and Infection. 2016; 22(3):277-e1.

6. Das S, Singh S, Tawde Y, Chakrabarti A, Shankarnarayan SA, Rudramurthy $S M$ et al. A selective medium for isolation and detection of Candida auris: an emerging pathogen. Journal of Clinical Microbiology. 2020. doi:10.1128/JCM.00326-20

\author{
Departamento de Parasitologia, Microbiologia e Imunologia, \\ Instituto de Ciências Biológicas, Universidade Federal de Juiz de \\ Fora, Brasil. \\ 2Departamento de Enfermagem Básica, Faculdade de \\ Enfermagem, Universidade Federal de Juiz de Fora, Brasil.
}

